\title{
PREGNANCY FEARS, SOCIAL DISTANCING AND CORONAVIRUS DISEASE: ANALYTICAL STUDY WITH SPECIAL REFERENCE TO INDIA ${ }^{1}$
}

DOI:10.47743/rdc-2021-1-0006

Mohleen KAUR ${ }^{2}$

\section{Abstract}

An authenticated attempt to understand the apprehensions of expectant mothers during COVID-19 rampant, the study primarily focuses on decoding the unpropitious ramification of such pandemic on the pregnant women. The process of giving birth to the child is itself risky, however, the existence of COVID-19 virus has made this process more complicated, tedious, and cumbersome. The social distancing practice has raised question upon the reproductive liability and has contemplated the immediate need of inclusion of maternal health provisions amongst the essential medical services in contemporary times. Research Methodology and Reference Materials: The author has employed doctrinal research methodology and has used existing qualitative data to uncover the plight of pregnant women in India. For reference, the study of the health reports laid down from time to time by the UNFPA, UNICEF and the Centre for Reproductive Rights, (India) is made. Conclusion: The present study helps us to delineate such means and methods which can help in improving the reproductive health of pregnant women.

Keywords: pregnancy, maternal health, female group, social distancing

\section{Introduction}

The COVID-19 rampant has assaulted the whole world and India is not an exception to it. Physical and mental breakdown of the people happening across the nation forces the layman to think and raise question on the accountability and the liability of the medical management system of India. The social fabric of India is such that there are amalgamation of traditional norms and scientific logics because of which our society reflects the fusion of regression and progression in the

\footnotetext{
${ }^{1}$ Presented at the International Conference on "Multidisciplinary Facets for Development in Health Laws", organized by Manipal University Jaipur India School of Law in collaboration with Bio Forensics Research Center, Italy, 16-17 July 2021.

${ }^{2}$ The author is working as Assistant Professor Law, at Chandigarh University, Mohali Punjab. The paper is written as research scholar by her in pursuit of her PhD degree.
}

ARticles. AnALYSIS AND REFLECTIONS 


\section{Mohleen KAUR}

contemporary times. The value of life was not felt, seen, and understood till the COVID-19 pandemic hit the world badly. No iota of doubt can be raised upon this fact that the primary repercussions of corona virus disease include the end number of deaths which occurred due to unavailability of oxygen cylinders inside the hospitals, but the ancillary affects include collapse of reproductive health-care system in the present hard times. Females are blessed by the universe to give birth to the future generations but due to the presence of corona virus infection, the process of pregnancy has become exasperating and, in some cases, has proved to be fatal for the pregnant ladies. Scarcity of beds, absence of helping hands including females doctors, mid-wives, nurses, lack of provision of abortion-facilities etc. are some of the important factors which can be held responsible for increased maternal mortality rate in India. Most of the poor and illiterate pregnant women who had no access to the basic amenities in relation to their pregnancy were forced to deliver child on the road. Imposition of lockdowns again and again aggravated the situation and caused unnecessarily a great mental havoc upon the minds of those females who were pregnant and remain struck inside their homes.

\section{Objective of the present study}

The present study helps us to understand the constraints faced by the pregnant women due to existing corona virus disease in contemporary times and to lay down such means and methods which can help the pregnant women to deliver their child safely and healthily without any risk It also aims to find answers to the questions whether the corona virus has increased the plethora of complications for the females bearing child in India; whether the practice of social distancing has increased the graph of the difficulties faced by the pregnant women or not and whether the corona virus infection has escalated the cases of maternal deaths and still births in India or not.

\section{Research domain}

To uncover the truth, sincere efforts are made to highlight and bring to the screen the obstacles and the deciding factors which have adversely created a negative impact upon the reproductive health of the pregnant women. A sincere endeavor is made to understand the real plight of female pregnant women struck at home, pregnant doctors who are serving inside the hospitals and pregnant migrant labourers who have lost their lives or the child in the womb due to lack of medical facilities. The present study aims to decode the fears and challenges faced by the expectant mothers in the present scenario along with putting up the solutions to their problems. 


\section{Female groups struck at home during lockdown}

Since times immemorial, women in the Indian society, have remained the victim of reproductive violations. From the traditional societies to the modern progressive societies the questions relating to the exercise of reproductive autonomy and reproductive choices in association with the pregnant women have always remained a debate of social, ethical and legal contest. The prodigy of the society is that the questions such as the right to bear the child, the right to decide the number and spacing of the children, the right to reproduce or not to reproduce are never answered solely by the pregnant women instead the State, the society, the law and the in laws' family including the husband takes every privilege to provide answers to such questions. There is always seen direct attack upon the notion "My Body My Choice". In such circumstances when already end number of interdictions and taboos are associated with the pregnant women, attack of COVID-19 pandemic has worsened the situation. The pregnant women struck inside the home during unplanned lockdowns were forced to compromise upon their right to privacy. Shared toilets and rooms did not give enough space to the expectant mothers to happily enjoy their period of pregnancy instead such women lived under the fear of getting infection of COVID-19 virus. Financial constraints pushed the women not to spend money on the medicines and other medical necessities which are mandatorily required during pregnancy. The increasing cases of unplanned pregnancies has become another strong reason for the rise in domestic violence cases.

\section{Female pregnant doctors deployed inside the hospitals}

The frontline healthcare forces such as female doctors, community workers, midwives and nurses are facing hardcore challenges these days. Most of the female doctors are giving duty inside the hospitals for more than ten hours a day. PPE kit is not easy to wear, hence the pregnant lady doctors must wear diapers to facilitate urination as they cannot remove their PPE kit again and again. Self-restriction is also imposed by the female pregnant doctors upon themselves for eating or drinking water again and again as they cannot remove the anti-covid shield from their face again and again. Dehydration, stress, fatigue, lack of Wash facilities etc. are some of the determining factors which adversely affect the pregnant female doctors. As per the news published in the Statesman on 3 June 2021, the latest report of the Indian Medical Association revealed that a total of 1478 doctors have died till now since the beginning of the pandemic in 2020, out of which approximately 748 doctors lost their lives in the first wave and approximately 730 doctors including the female pregnant doctors died during the second wave of COVID-19 rampant in India ${ }^{3}$.

${ }^{3} 730$ doctors, 2021, p. A12.

Articles. Analysis and Reflections 


\section{Female pregnant migrant labourers of India}

The migrant labourers faced hard times during COVID-19 pandemic. Unwanted predicament of mobility raised strong concerns for removing the financial blockades for those people who lived below poverty line during this deadly attack of corona virus disease. Lack of public toilets on the roads and the shift in the services of registered medical practitioners resulted in total neglect of pregnant migrant labourers in India. Majority of the migrant labourers were forced to leave their working places and move towards their home states as they were not able to fulfil their fundamental needs of food, clothing, and shelter during such crisis. Absence of money, beds inside the hospitals, lack of clean drinking water and lack of wash facilities are some of the important reasons which pushed the female pregnant migrant labourers to deliver their child on roadside because of which most of the women were forced to die on the roads before they could reach their home state. There was seen rise in the cases of still births in India during COVID crisis as many pregnant women delivered their babies on the road without any medical help.

\section{Challenges faced by the pregnant women due to COVID-19}

When talking about the plight of the pregnant women, it becomes essential here to talk about the hindrances, constraints and challenges which are responsible for increasing the fears in the minds of the expectant mothers thereby making the process of delivery of child hefty and burdensome. Some of such factors are discussed as following:

\section{- No documentation of statistics relating to cases of mother to child transfer}

From the first wave of the COVID-19 till the second wave we all have witnessed the time of more than one year, but during this time absence of well authenticated data which can be evidenced and documented in relation to COVID-19 transfer from mother to child, acted as stumbling block in providing basic reproductive services to the pregnant women in India. There exists iota of doubt and dotages of superstition regarding the fact whether the pregnant mother infected with COVID-19 passes the infection to his/her child or not. Studies done till now are unable to clearly explain the effect of COVID-19 upon the child inside the womb, the impact upon the child who is born but is surviving close to the mother who got infection after delivery, the output of COVID-19 vaccine when given to such mothers etc.

\section{- Shift in the duties of registered medical practitioners and less pre-natal check-ups}

Due to COVID crisis, there is seen shift in the duties of the medical surgeons, medical staff including the nurses, community workers and doctors. The jobs of the 
Pregnancy fears, social distancing and Coronavirus disease...

doctors have turned into a twenty-four-seven process without any break or rest. As a result of this, the doctors deployed inside the hospitals are not able to give complete attention to the delivery cases. Abortion cannot be performed by every doctor, only those surgeons who have special experience in this field can provide such services. Absence of abortion facilities during these days due to scarcity of specialized surgeons pushed the pregnant women to compromise on their reproductive choice and give birth to such children which otherwise remained unwanted for them. The factors like unplanned lockdowns and fear of catching infection threatened the pregnant ladies because of which they did not go for regular pre-natal check-ups to their respective doctors or hospitals. The complications may get increased when diagnosis of the pregnancy related concerns become impossible due to infrequent prenatal check-ups inside the hospitals.

\section{- High risk of infection due to COVID-19 attack on pregnant women aged forty-five or older}

The pregnant women and the ladies who are suffering from diabetes, asthma, heart related complications or already have undergone miscarriage or abortion are enduring physical and mental stress which causes an unnecessarily great mentalhavoc upon their minds. All such women including the ones who got pregnant in their late forties have started living under fear of death during the present times. As the corona virus disease blocks the respiratory system of the human being so the risk of the death of the child who is inside the womb of the infected mother gets multiplied. Sometimes, due to the infection, the circumstances become so critical that it becomes very hard for the doctors to decide as to whose life should be saved first: the mother or the child.

\section{- Pregnancy - interdictions and taboos in India}

The population of India stays obedient to existing customs, ethical, social, and cultural norms till today. End number of taboos and interdictions are associated with the whole process of pregnancy in modern progressive times as well. Reproduction instead of being viewed as scientific, rational, and palpable experience of giving birth to future generations, in some regions of India is still viewed as the "Blessing or Curse Affair" in light of the "Karmic Accounts" of the person keeping in mind the actions of the concerned human being in his past and the present lives. These interdictions become more stronger when with the help of the relevant scientific technologies, it is found that the child inside the womb is suffering from substantial foetal abnormalities, or the circumstances are such that the child is found to be physically or mentally handicap after his/her birth. All such taboos prevent the pregnant women especially residing in the rural areas from exhibiting their trust in modern scientific

ARTICLES. ANALYSIS AND REFLECTIONS 
techniques to deal with complicated cases of pregnancies where the threat to life of mother or foetus inside the womb is apparently visible.

Most of the people of India portray COVID-19 pandemic as universal imprecation thereby believing that the natural forces have directly attacked upon human race as a matter of curse and prevention, protection and survival in such circumstances is hard task. In such scenario, the mental health of the pregnant women gets negatively affected. It is very important to understand that the healthy mental and physical make-up can only help the pregnant women to deliver a healthy child. In such scenario, serious concerns are raised when the woman who is pregnant is forced to take unnecessarily a lot of pressure on her mind or is pushed to live under the fear of getting caught by COVID-19 infection, as all such pressures exasperate the mental and physical health of the expectant mother and contribute to miscarriage or abortion of the child in contemporary times. Healthy and fearless mother can raise her child happily but present circumstances where the news of death of people due to COVID-19 dominates our newspapers and media, it has become difficult for the expectant mothers to stay calm, positive, happy, stable, and cheerful. Maternal mortality rate comes down when the child is delivered with the help of the registered medical practitioners and proper care is administered to the pregnant women after delivery inside the hospitals.

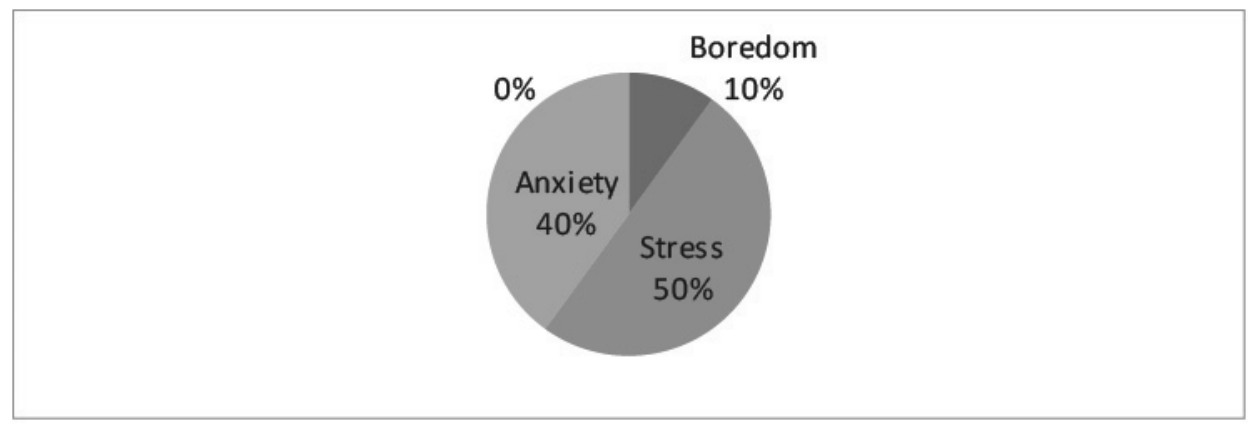

\section{Factors affecting maternal mental health during COVID-19 crisis ${ }^{4}$}

The above-mentioned pie-chart clearly reveals that approximately $47 \%$ of the pregnant females of India suffer from self-imposed stress during the COVID crisis, around $38 \%$ of the women are suffering from anxiety disorders, $9 \%$ of the female groups struck inside the homes are facing boredom and $6 \%$ of the pregnant females are suffering from loneliness during this attack of corona virus disease.

\footnotetext{
${ }^{4}$ Rajkumar, 2020, p. 52.
} 
Pregnancy fears, social distancing and Coronavirus disease...

\section{- Practice of social - distancing and pregnant women}

The practice of social distancing has aggravated the pregnancy problems and has directly attacked upon the mental health of the pregnant women. Once found that the expectant mother is suffering from corona virus disease and needs to be admitted inside the hospitals, the helping hands including the nurses and healthcare workers become bit reluctant in going near to such infected mother under the fear of catching the infection. Most of the COVID-19 wards especially in rural areas have become haunting places with no or very few human beings providing health care services in such wards. Lack of wash facilities inside the hospitals and scarcity of basic reproductive amenities accompanied with the practice of social distancing breaks down the courage of the pregnant women admitted inside the hospitals because of which the women sometimes feel like committing suicide in contemporary times. There is a clear line of demarcation between social distancing vs. social boycott, but social outcaste of the infected pregnant female under the garb of practice of social distancing not only puts unnecessary trauma on the mind of the expectant mother but sometimes pushes her to abort the child as well.

\section{Present status of maternal mortality rate due to COVID-19 in India}

As per the latest report titled, "Direct and Indirect Effects of the COVID-19 Pandemic and Response in South Asia" by UNICEF, World Health Organization (WHO) and the UN Population Fund, February 2021, South Asia has reported more than 12 million COVID-19 cases out of which 10.9 million cases are in India itself. The report also specifies that the graph of the maternal and the child mortality rate is seen to rise as the number of deaths among children aged five years and less is estimated to increase by a total of 2,28,641 across the six South Asian countries, with the greatest hike in India $(1,54,020-15 \%)$ and in Pakistan $(59,251-14 \%)$. Further, due to disrupted reproductive services, the number of stillbirths is also predicted to increase. The largest number of still births occurs in India i.e. (60,179-10\% increase) followed by Pakistan $(39,752-11 \%$ increase) and Bangladesh (5,502-3\% increase) respectively. Similarly, the number of maternal deaths has also taken toll with highest rise in India $\left(7,750-18 \%\right.$ increase) and Pakistan $\left(2,069-21 \%\right.$ increase) as compared to the last year ${ }^{5}$.

\section{Impact of COVID-19 vaccination on pregnant women in India}

No serious repercussions of COVID-19 vaccination are seen on the females including the adolescent girls, pregnant ladies, and breast-feeding mothers in India.

\footnotetext{
${ }^{5}$ Singh, 2021, COVID-19 disruptions, para. 6.
}

ARticles. Analysis AND REFLECTIONS 
Dr. Shilpa Ghosh, Director OBS and Gynecology, Akash HealthCare, when asked about the effect of COVID-19 vaccination upon the pregnant women clearly revealed that although studies regarding the same are going on still no hardcore or negative consequences are seen when COVID-19 vaccination is administered to the pregnant women, the breastfeeding mothers and the school going girls. She also clarified that no negative impact of COVID-19 vaccination is witnessed on the menstrual cycle of the females so the women who are planning to conceive child may undergo vaccination before getting pregnant ${ }^{6}$.

\section{Analysis}

The existing set of facts and observations as laid above clearly define the impact of corona virus disease upon the pregnant women in India. The detailed study along with the authentic evidence about the aftermath of corona virus disease on the pregnant women in India needs to be well documented. Suspension of basic social services including the discontinuation of the public transport system, diminishing approachability of WASH supplies and hearsay of debunking myths associated with such disease and shift in the duties of the registered medical practitioners can be seen as four important factors responsible for disrupted reproductive services in India. Poverty, financial insecurity, no access to digital platforms, lack of oxygen cylinders and beds inside the hospitals for the pregnant women are important reasons which have made the present situation more dreadful. The need of the hour is to listen to the guidelines issued by WHO and UNICEF from time to time so that maximum lives including the ones in the mother's womb can be saved in such hard circumstances.

\section{Conclusion and suggestions}

In the end it can be summed up that any nation can gain recognition globally and can emerge as superpower only when the government and people of that nation abide by the principle of Greatest Happiness of Greatest Number. Pregnancy is benchmark and reflection of essence of humanity on this earth hence the safety of the human beings along with the safety of the pregnant women has become priority these days. Strict enforcement of COVID-19 guidelines, provision of emergency public transport services for pregnant women, enhancement of digital platforms to provide basic aid and help to pregnant ladies, prioritizing reproductive healthcare services, expansion of the retail outlets which can provide basic reproductive amenities,

${ }^{6}$ Dr. Ghosh, 2020.

CONSTITUTIONAL LAW REVIEW 
Pregnancy fears, social distancing and Coronavirus disease...

advocating the need for the removal of taxes on reproductive medical products etc. are some of the necessary steps which can be taken to improve the reproductive health of pregnant women in India. The present times demand from us to stand united with each other so that the lives of maximum people can be saved in such hard times. 